\title{
Genetic diversity of Chamaecrista fasciculata (Fabaceae) from the USDA germplasm collection
}

\author{
Erika Bueno ${ }^{1}$, Ted Kisha², Sonja L. Maki ${ }^{3,4}$, Eric J. B. von Wettberg ${ }^{1 *}$ (D) and Susan Singer ${ }^{3,5}$
}

\begin{abstract}
Objective: Chamaecrista fasciculata is a widespread annual legume across Eastern North America, with potential as a restoration planting, biofuel crop, and genetic model for non-papillinoid legumes. As a non-Papilinoid, C. fasciculata, belongs to the Caesalpiniod group in which nodulation likely arose independently of the nodulation in Papilinoid and Mimosoid legumes. Thus, C. fasciculata is an attractive model system for legume evolution. In this study, we describe population structure and genetic diversity among 32 USDA germplasm accessions of C. fasciculata using 317 AFLP markers developed from 12 primer pairs, to assess where geographically there is the most genetic variation.

Results: We found that the C. fasciculata germplasm collection fall into four clusters with admixture among them. After correcting for outliers, our analysis shows two primary groups across Eastern and Central North America. To better understand the population biology of this species, further sampling of the full range of this widespread species is needed across North America, as well as the development of a larger set of markers providing denser coverage of the genome. Further sampling will help clarify geographical relationships in this widespread temperate species.
\end{abstract}

Keywords: Chamaecrista, Caesalpinoid, Population genetics, ALFP markers, Genetic diversity

\section{Introduction}

Genetic diversity of germplasm collections serves as an important resource for the conservation and maintenance of both wild and cultivated plants and can be particularly useful for the development of new potential crops. One such species is Chamaecrista fasciculata, or partridge pea, which is a member of the economically important Leguminosae family. The species belongs to the subfamily Caesalpinioideae; the common ancestor of Papilionoid legumes (soybean, Medicago, and Lotus) which diverged approximately 60 million years ago (Legume Phylogeny Group, [20, 21] from these groups. There is growing interest in implementing Chamaecrista as a complementary model for legume evolution due to its relatively small genome size, phylogenetic position, ability to form nodules, and flower development; all of which would provide fundamental knowledge on the evolutionary origins of legume traits [29]. A genome sequencing project is currently underway for C. fasciculata (Steve

\footnotetext{
*Correspondence: ebishopv@uvm.edu

${ }^{1}$ Plant and Soil Science, University of Vermont, Burlington, VT, USA

Full list of author information is available at the end of the article
}

Cannon, Pers. Comm.), which is one of the only annual temperate species with a compact growth form in the large genus of $\sim 330$ mostly long-lived tropical tree and shrub species.

The partridge pea (C. fasciculata), is a North American annual legume with a widespread distribution that ranges from the Northern Great Plains to Central Mexico. In the U.S. C. fasciculata, can be found growing from southern New England to Florida and westward into New Mexico and Oklahoma [15]. It is self-compatible and has a high outcrossing rate of $80 \%[10,12]$. The plant produces large yellow flowers that are exclusively pollinated by carpenter bees and bumblebees [1]. Seeds are dispersed short distances from parents $(<2.5 \mathrm{~m})$ via explosive dehiscence [10]. Below ground, C. fasciculata forms nodules in response to nitrogen fixing bacteria known as rhizobium [22]. Unlike other legume crops, the genus Chamaecrista has not undergone any whole genome duplications [2] since its divergence from the Papilionoideae and has a generally smaller genomes (ca. $650 \mathrm{Mb}$ in C. fasciculata). Working with fewer copies of genes in a model system such as $C$. fasciculata makes genetic approaches substantially easier, potentially enhancing the rate of discovery 
in legume crops. As the only temperate annual in a large tropical tree genus, a wealth of information exists on the ecology of $C$. fasciculata including the characterization of locally adaptive traits in response to climate change, key pollinators, and gene flow and genetic structure among naturally occurring populations $[4-6,10,11,13,14,30$, 31]. Additionally, the genus Chamaecrista has independently evolved the ability to form nodules, thereby creating a unique opportunity to investigate the origins of nodulation and mutualistic interactions in Leguminosae [3]. Therefore, expanding on the genomics of C. fasciculata as a non-papilionid model legume is a key step into understanding the evolution of legume traits.

Here, we characterize genetic variation in the USDA collection of $C$. fasciculata comprising of 32 accessions originating from a range of populations in the U.S. that span its geographic distribution. Using Amplified Fragment Length Polymorphism (AFLP) markers [33], we show that there are four clusters in the germplasm collection with minimal genetic differentiation among groups.

\section{Main text \\ Methods \\ Germplasm collection}

Accessions were selected from the USDA GRIN repository. In total, we assembled a total of 32 accessions which is a representative of all available accessions in the repository. Because the samples were donated to USDA prior to 1992, they lack precise location information. Thus, we were only able to determine the U.S. state from which they originated. All samples were of C. fasciculata var fasciculata, as C. fasciculata var macrospermum is restricted to Virginia, a state with no samples in this dataset.

\section{AFLP marker development}

Freeze-dried, leaf tissue samples from 32 accessions were pulverized in a SPEX SamplePrep 2000 Geno/Grinder ${ }^{\circledR}$, and DNA was extracted using the Wizard ${ }^{\circledR}$ Magnetic 96 DNA Plant System (Promega). Amplified Fragment Length Polymorphism (AFLP) markers were generated using locally developed procedures based on technology by Vos et al. [33] and following modifications in Johnson et al. [18] and Greene et al. [16]. We performed a restriction double digest in $25 \mu \mathrm{l}$ reactions containing $250 \mathrm{ng}$ of DNA, 1X Purified BSA, 5.0 U each of EcoRI and MseI restriction enzymes (New England BioLabs) and $1 \mathrm{X}$ NE Buffer 4 . To verify complete digestion, re ran $15 \mu$ l of the restriction digest reaction on a $1.5 \%$ agarose gel.

Adapter sequences (EcoRI-Fwd, 5'-ctc gta gac tgc gta cc; EcoRI-Rev, 5'-aat tgg tac gca gtc tac; MseI-Fwd, 5'-gac gat gag tcc tga g, and MseI-Rev, 5'-tac tca gga ctc at) were purchased from Eurofins MWG/Operon (Huntsville,
Alabama). After diluting each adapter pair to $100 \mathrm{pM} / \mu \mathrm{l}$ (EcoRI) or $200 \mathrm{pM} / \mu \mathrm{l}(\mathrm{MseI})$, we combined them in equal amounts, and let them anneal for $1 \mathrm{~h}$ at $37^{\circ} \mathrm{C}$ and cool to room temperature. We then diluted the annealed pairs to $5 \mathrm{pM} / \mu \mathrm{l}(E c o \mathrm{RI})$ and $50 \mathrm{pM} / \mu \mathrm{l}(\mathrm{MseI})$, aliquoted to $100 \mu \mathrm{l}$ amounts for frozen storage for possible future use.

Following previous procedures in Johnson et al. [18] and Greene et al. [16], we performed a ligation step at $20^{\circ} \mathrm{C}$ for $2 \mathrm{~h}$ in a $20 \mu \mathrm{l}$ reaction containing $10 \mu \mathrm{l}$ of the remaining restriction digest, 5 pMoles EcoRI adapter, 50 pMoles MseI adapter, 0.5 mM ATP, 80 cohesive end Units of T4-ligase, and 1X T4 Ligase Buffer (New England BioLabs). We diluted the completed ligation reaction to 10:1 for pre-amplification. Both pre-amplification and selective amplification were done using an ABI 9700 thermocycler using cycling programs described by Vos et al. [33] in $10 \mu \mathrm{l}$ reactions. Two millilitre of the diluted pre-amplification product (10:1) was used for selective amplification. We used twelve separate primer pairs for selective amplification (Eacg/Mcaa, Eagg/Mcaa, EacaMcag, EaccMcat, Eacg/Mctg, Eagc/Mctt, Eaca/Mcta, Eacc/Mctc, Eacg/Mcac, Eagg/Mctg, Eaca/Mcat, Eacc/Mcaa) where the last 3 letters indicate the selective nucleotides following the E-EcoRI and M_MseI primer sequences). Marker fragments were visualized on a LI-COR 4300 DNA Analyzer (LI-COR Biosciences). We scored marker loci as either present or absent based on printed images.

\section{Data analysis}

We created a graphical display of accession relationships with NTSys-pc software [27] using Jacard's coefficient. The tree was constructed using Q-values that were outputted from a STRUCTURE analysis (see below) at $\mathrm{K}=4$ and Prevosti's distance coefficient [25] which substitutes Q-value fractions for allele frequencies at a single AFLP locus.

To examine population structure we used STRUCTU RE v2.3.3 [8, 9, 26] and the widely applied technique developed by Evanno et al. [7]. Ten replications with a burn-in of 20,000 iterations followed by 20,000 additional iterations were used at each $\mathrm{K}$ level until results indicated lowered and less erratic values for $\mathrm{P}(\mathrm{X} \mid \mathrm{K})$. The parameter set included the ADMIXTURE model with allele frequencies correlated, and a RECESSIVE ALLELES model that is essential for dominant loci like AFLPs. Average Q-plots over the ten replications were calculated using the associated software CLUMPP [17], and graphic displays of population structure were developed from the q-frequencies of the mean of 10 runs using DISTRUCT software [28]. We analyzed genetic diversity in Genalex $6.5[23,24]$ and checked them in AFLP-SURV 1.1 [32] (not shown). Lastly, we performed a Principal 
Components Analysis (PCA) for clustering using binary assignments in Genalex.

\section{Results}

\section{Analyses of population structure}

AFLP analysis resulted in a total of 317 polymorphic loci. STRUCTURE analysis combined with the technique of Evanno et al. [7] indicated the most probable number of distinct populations at $\mathrm{K}=4$ (Figs. 1 and 2, Table 1, Additional file 1: Figure S1a, b). Separation was, for the most part, based on latitude with some anomalies. Consequently, we named these groups Central (US), South, AK/MS, and Texas. While the accessions from Kansas, Nebraska, New Jersey, and Minnesota (Central US group) were mostly separated from those of Arkansas and Mississippi, two accessions from Arkansas, and one from Mississippi were grouped apart from the others, and then placed into our AR/MS cluster. A sample from Texas also formed a separate group, although some samples from other states, such as Minnesota, showed some admixture with this group.

We identified seven individuals as considerably admixed among at least two of the groups. A Principal Component Analysis (PCA, Fig. 2) showed the three individuals from the AR-MS group differentiated on the first axis, and differentiation along a latitudinal axis on the second axis. Although STRUCTURE combined the more Northern accessions to the first two groups (our Central and South groups), the PCA suggests a subtle latitudinal cline in diversity, overwhelmed by differentiation among multiple groups in the Southern US. This pattern of greater Southern diversity and differentiation is consistent with glacial refugia in the Southern U.S. during the last glacial maxima, and admixture as populations migrated back to deglaciated areas in the more Northern US.

\section{Genetic diversity analysis}

Overall, we found some genetic differentiation among the four groups in the USDA Chamaecrista fasciculata germplasm collection. In total, we analyzed the genetic variability of 317 loci from 32 C. fasciculata accessions (Table 2). The overall Pairwise genetic distance PhiPT value was $0.207(\mathrm{P}=0.001)$. The Analysis of Molecular Variance (AMOVA) based on PhiPT values indicated that $79 \%$ of the variance comes from within populations (estimated variance $=11.84$ ) while $21 \%$ of the variance comes from among populations (estimated variance $=3.11$ ). Mean Shannon's diversity index across all populations was $0.24( \pm 0.11)$.

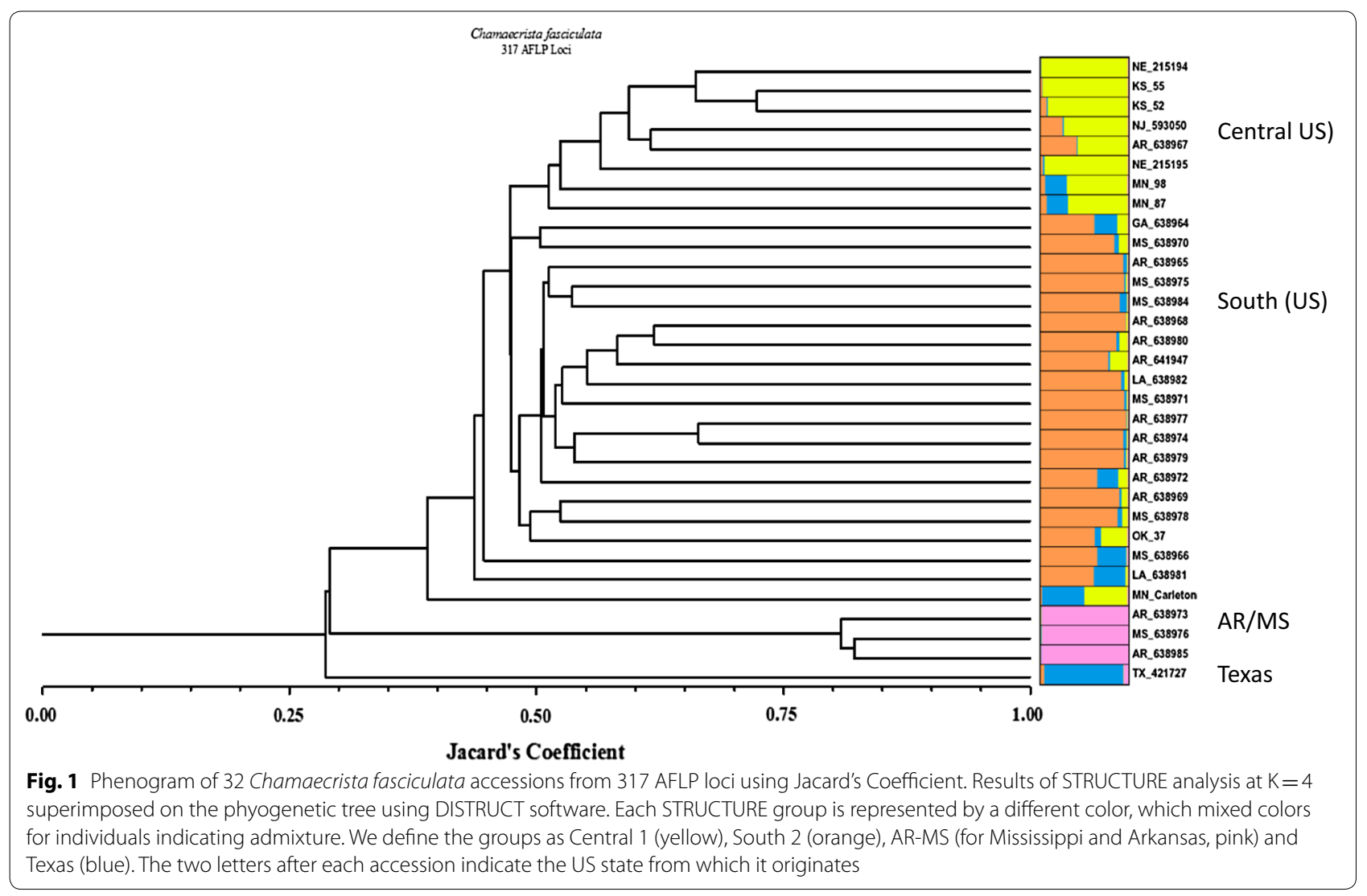




\section{Principal Coordinates (PCoA)}

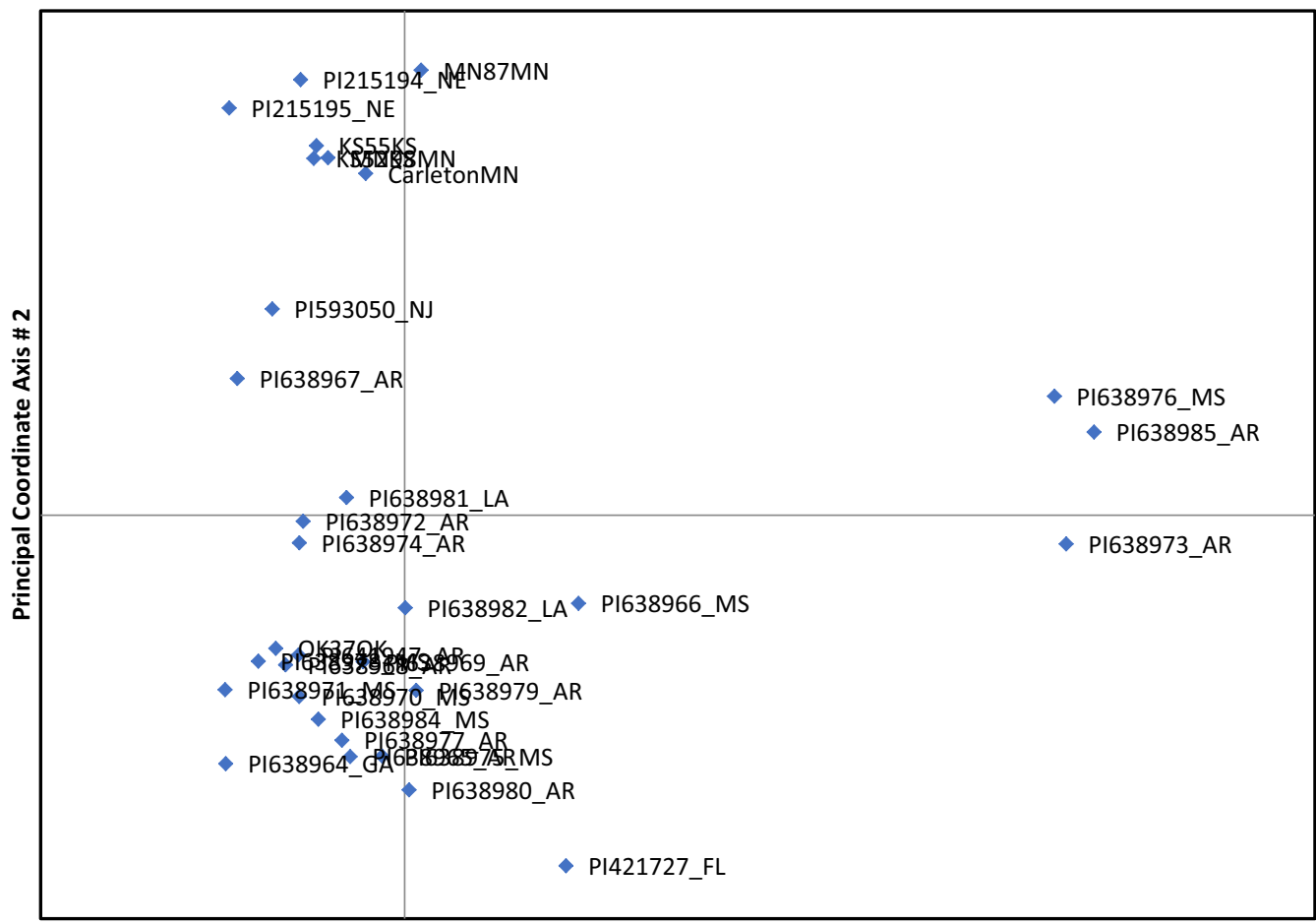

Principal Coordinate Axis \#1

Fig. 2 PCoA plot of 32 USDA Chamaeacrista fasiculata accessions. Three accessions from the US states of Mississippi (MS) and Arkansas (AR) form a group (MS-AR) that was also detected in our STRUCTURE analysis (Fig. 1). Accessions are named by USDA GRIN ID number and the US state from which they originate

\section{Discussion}

AFLP markers were used to estimate genetic diversity among 32 C. fasciculata accessions sampled across its geographical distribution. The patterns of differentiation we observed in C. fasciculata likely result in part from migration in response to repeated patterns of glacial activity. The differentiation found in the more Southern US states is likely a result of differentiation in glacial refugia, such as on different sides of the Appalachian mountain chain or Ozark mountains, with more Northern populations resulting from post-glacial advances northward and possible admixture from different glacial refugia. A similar AFLP analysis of Phaseolus polystachios, the North American Wild Kidney Bean, and the only Phaseolus species native to temperate North America set apart an accession from Texas which was later given species status as Phaseolus texensis ([19], and unpublished).

Chamaecrista fasciculata is a very widespread plant in eastern and central North America, occurring in a variety of habitats from mixed prairies to disturbed habitats, to unique local ecosystems such as mid-Atlantic serpentine barrens and South Florida Karstic pine rocklands. Such widespread occurrence and broad adaptation could make it useful as a component of mixed biofuel plantings as well as habitat restoration plantings and ecological and evolutionary studies. Based on our findings, the current collection, although diverse, likely does not capture the full range of variation present in this ecologically diverse species. In particular, more precise sampling from particular habitats, may show unique patterns of differentiation. Similarly, more thorough sampling at the edge of the geographic range of the species may find outlying populations, or uncover introgression with more tropical Chamaecrista species, such as $C$. nictitans or C. lineata var. keyensis, which is endangered in the Florida Keys. The outlying Texas group may be consistent with rangeedge differentiation of populations. Thus, we recommend further collecting to improve the value of this collection for a variety of uses, from research to restoration, to biofuels. 
Table 1 Group assignments, based on STRUCTURE output analyzed in DISTRUCT

\begin{tabular}{|c|c|c|c|c|c|c|}
\hline Name & Geographic location & Assigned group & AvgG1: Central US & AvgG2 South US & AvgG3 AR/MS & AvgG4 TX \\
\hline MN87MN & Minnesota & 1 & 0.84766 & 0.10144 & 0.00464 & 0.04622 \\
\hline PI638984_MS & Mississippi & 1 & 0.902 & 0.0106 & 0.00286 & 0.0845 \\
\hline PI638972_AR & Arkansas & 1 & 0.73666 & 0.10594 & 0.00338 & 0.15402 \\
\hline CarletonMN & Minnesota & 1 & 0.90492 & 0.0676 & 0.00538 & 0.02212 \\
\hline PI421727_FL & Florida & 1 & 0.78614 & 0.00676 & 0.06742 & 0.13968 \\
\hline PI215194_NE & Nebraska & 2 & 0.0045 & 0.9867 & 0.00254 & 0.00628 \\
\hline KS55KS & Kansas & 2 & 0.0062 & 0.98176 & 0.00414 & 0.00792 \\
\hline KS52KS & Kansas & 2 & 0.01128 & 0.97022 & 0.00372 & 0.01476 \\
\hline PI593050_NJ & New Jersey & 2 & 0.06028 & 0.7166 & 0.00362 & 0.21948 \\
\hline PI215195_NE & Nebraska & 2 & 0.016 & 0.95024 & 0.00234 & 0.03138 \\
\hline MN98MN & Minnesota & 2 & 0.19864 & 0.7373 & 0.02154 & 0.0425 \\
\hline PI638973_AR & Arkansas & 3 & 0.00358 & 0.0024 & 0.99056 & 0.00342 \\
\hline PI638976_MS & Mississippi & 3 & 0.00352 & 0.00656 & 0.98712 & 0.00278 \\
\hline PI638985_AR & Arkansas & 3 & 0.00202 & 0.00226 & 0.99362 & 0.0021 \\
\hline PI638964_GA & Georgia & 4 & 0.0106 & 0.01294 & 0.00222 & 0.97424 \\
\hline PI638970_MS & Mississippi & 4 & 0.04758 & 0.00958 & 0.00418 & 0.9387 \\
\hline PI638965_AR & Arkansas & 4 & 0.28276 & 0.01834 & 0.0052 & 0.69372 \\
\hline PI638968_AR & Arkansas & 4 & 0.01312 & 0.04472 & 0.00324 & 0.93894 \\
\hline PI641947_AR & Arkansas & 4 & 0.03324 & 0.04714 & 0.00398 & 0.91562 \\
\hline PI638971_MS & Mississippi & 4 & 0.2241 & 0.01648 & 0.00258 & 0.75686 \\
\hline PI638977_AR & Arkansas & 4 & 0.01602 & 0.00734 & 0.00304 & 0.97358 \\
\hline PI638974_AR & Arkansas & 4 & 0.03314 & 0.00978 & 0.00808 & 0.94906 \\
\hline PI638979_AR & Arkansas & 4 & 0.08862 & 0.02068 & 0.0084 & 0.88232 \\
\hline PI638978_MS & Mississippi & 4 & 0.08274 & 0.02068 & 0.00266 & 0.89388 \\
\hline OK37OK & Oklahoma & 4 & 0.08768 & 0.02706 & 0.00282 & 0.8824 \\
\hline Pl638967_AR & Arkansas & Admixed & 0.02898 & 0.46856 & 0.00282 & 0.49962 \\
\hline PI638975_MS & Mississippi & Admixed & 0.56434 & 0.01114 & 0.01008 & 0.41442 \\
\hline PI638980_AR & Arkansas & Admixed & 0.53272 & 0.03362 & 0.00578 & 0.42788 \\
\hline Pl638982_LA & Louisiana & Admixed & 0.50036 & 0.0193 & 0.0153 & 0.46506 \\
\hline PI638969_AR & Arkansas & Admixed & 0.34768 & 0.02832 & 0.0079 & 0.61608 \\
\hline PI638966_MS & Mississippi & Admixed & 0.48354 & 0.01372 & 0.20876 & 0.29398 \\
\hline PI638981_LA & Louisiana & Admixed & 0.60256 & 0.10074 & 0.00492 & 0.29174 \\
\hline
\end{tabular}

Our STRUCTURE analysis detected four groups, or populations, which we have named Central (group 1, yellow in Fig. 1), South (group 2, orange in Fig. 1), AR/MS (group 3, Arkansas/Mississippi, pink), and Texas (TX, group 4, blue). We give the percent membership of each accession to each STRUCTURE group to show the extent of admixture

\section{Limitations}

The AFLP markers that were used in this study have several limitations such as being dominant rather than co-dominant, occurring at random locations in the genome that are difficult to tie to a genomic region and being limited to a few hundred total loci. New technologies, such as genotyping-by-sequencing and next generation sequencing based approaches that develop single nucleotide polymorphisms do overcome these challenges. Secondly, the set of lines examined is small in total number, with 32 being marginal for inference about population genetic patterns. Third, the USDA collection was assembled before 1992, when GPS units became available. Consequently, the passport data 
Table 2 Genetic diversity in 317 AFLP loci in 32 USDA accessions of Chamaecrista fasciculata

\begin{tabular}{|c|c|c|c|c|c|c|c|}
\hline & $\mathbf{N}$ & $\mathrm{Na}$ & $\mathrm{Ne}$ & I & $\mathrm{H}$ & Uh & $\% \mathrm{P}$ \\
\hline \multicolumn{8}{|l|}{ Pop } \\
\hline \multicolumn{8}{|c|}{ Central US } \\
\hline Mean & 5.000 & 1.297 & 1.402 & 0.355 & 0.239 & 0.298 & \multirow[t]{2}{*}{62.71} \\
\hline SE & 0.000 & 0.086 & 0.033 & 0.026 & 0.018 & 0.022 & \\
\hline \multicolumn{8}{|c|}{ South (US) } \\
\hline Mean & 6.000 & 0.932 & 1.236 & 0.209 & 0.140 & 0.168 & \multirow[t]{2}{*}{38.14} \\
\hline SE & 0.000 & 0.084 & 0.031 & 0.025 & 0.017 & 0.021 & \\
\hline \multicolumn{8}{|l|}{ AR/MS } \\
\hline Mean & 3.000 & 0.466 & 1.081 & 0.065 & 0.045 & 0.068 & \multirow[t]{2}{*}{10.17} \\
\hline SE & 0.000 & 0.062 & 0.022 & 0.018 & 0.012 & 0.019 & \\
\hline \multicolumn{8}{|l|}{ Texas } \\
\hline Mean & 11.000 & 1.263 & 1.264 & 0.267 & 0.169 & 0.186 & \multirow[t]{2}{*}{59.32} \\
\hline SE & 0.000 & 0.085 & 0.028 & 0.023 & 0.016 & 0.017 & \\
\hline \multicolumn{8}{|c|}{ Admixed } \\
\hline Mean & 7.000 & 1.246 & 1.332 & 0.306 & 0.201 & 0.235 & \multirow[t]{2}{*}{58.47} \\
\hline SE & 0.000 & 0.086 & 0.032 & 0.025 & 0.017 & 0.020 & \\
\hline \multicolumn{8}{|c|}{ Grand mean and SE over loci and pops } \\
\hline \multicolumn{8}{|l|}{ Total } \\
\hline Mean & 6.400 & 1.041 & 1.263 & 0.240 & 0.159 & 0.191 & 45.76 \\
\hline SE & 0.109 & 0.038 & 0.014 & 0.011 & 0.008 & 0.009 & 9.89 \\
\hline
\end{tabular}

$\mathrm{Na}=$ no. of different alleles, $\mathrm{Ne}=$ no. of effective alleles $=1 /\left(p^{\wedge} 2+q^{\wedge} 2\right), I=$ Shannon's Information $\operatorname{lndex}=-1^{*}\left(p^{*} \operatorname{Ln}(p)+q^{*} \operatorname{Ln}(q)\right), H=\operatorname{diversity}=1-\left(p^{\wedge} 2+q^{\wedge} 2\right)$, $\mathrm{uh}=$ unbiased diversity $=(\mathrm{N} /(\mathrm{N}-1))^{*} \mathrm{~h}$ (where for haploid binary data, $\mathrm{p}=$ Band Freq. and $\left.\mathrm{q}=1-\mathrm{p}\right)$, and \% $\mathrm{P}=$ percent polymorphic loci

for the accessions we assessed is limited to U.S. State, rather than more precise locations. Our work suggests that efforts to expand the USDA germplasm collection for Chamaecrista and improve the associated passport data would be quite useful for a number of research applications.

\section{Additional file}

Additional file 1: Figure S1. Plots from the software STRUCTURE of A) $\ln P(X \mid K)$ indicating the highest probability at $K=4$, and $(B)$ graph of $d K$ vs $K$ from technique of Evanno et al. [7] indicating most probable population subdivisions at $K=2$ and $K=4$. Based on the Evanno et al [7] technique, we find 4 to be the best number of populations.

\section{Authors' contributions}

EB: Performed analyses and co-wrote draft. TK: Performed molecular work, performed analyses, and co-wrote draft. SM Performed DNA extractions and helped assemble materials. EvW: co-performed analyses, co-wrote draft. SRS: Designed study, assembled materials, and co-wrote draft. All authors read and approved the final manuscript.

\section{Author details}

${ }^{1}$ Plant and Soil Science, University of Vermont, Burlington, VT, USA. ${ }^{2}$ USDA ARS, Pullman, WA, USA. ${ }^{3}$ Biology and Cognitive Science Department, Carleton College, Northfield, MN, USA. ${ }^{4}$ Plant and Earth Science Department, University of Wisconsin-River Falls, River Falls, WI, USA. ${ }^{5}$ Department of Biology, Rollins College, Winter Park, FL, USA.

\section{Acknowledgements}

We would like to thank the students of von Wettberg's Population Genetics PBC 4553 and PCB 5686 classes for helpful comments.

\section{Competing interests}

The authors declare that they have no competing interests.

\section{Consent to publish}

NA, the study involved no human subjects.

Data availability

Data is available in dryad, associated with this manuscript. We have made the data available in researchgate.net as well. The data is also directly available from the corresponding author based on any reasonable request. Accessions (Table 1) are available from the USDA GRIN repository at: https://www.ars-grin. gov/npgs/.

\section{Ethics approval and consent to participate}

NA, the study involved no human participants.

\section{Funding}

This work was supported by NSF- DEB-0746571 to SRS. Von Wettberg acknowledges funding support from the USDA-NIFA-NNF program- Grant Number 2011-38420-20053 and from USDA-NIFA-Hatch for data analysis and support to Erika Bueno. The funding bodies had no role in the design of the experiment, interpretation of the data, or writing of the manuscript.

\section{Publisher's Note}

Springer Nature remains neutral with regard to jurisdictional claims in published maps and institutional affiliations.

Received: 13 November 2018 Accepted: 22 February 2019

Published online: 04 March 2019 


\section{References}

1. Campbell JW, Irvin JH, Ellis JD. Bee contribution to partridge pea (Chamaecrista fasciculata) pollination in Florida. Am Midland Naturalist. 2018;179(1):86-93.

2. Cannon SB, Ilut D, Farmer AD, Maki SL, May GD, Singer SR, Doyle JJ. Polyploidy did not predate the evolution of nodulation in all legumes. PLOS ONE. 2010;5(7):e11630.

3. Cronk QC. Legume flowers bear fruit. Proc Natl Acad Sci. 2006:103(13):4801-2.

4. Etterson JR, Shaw RG. Constraint to adaptive evolution in response to global warming. Science. 2001;294(5540):151-4.

5. Etterson JR. Evolutionary potential of Chamaecrista fasciculata in relation to climate change. I. Clinal patterns of selection along an environmental gradient in the Great Plains. Evolution. 2004;58(7):1446-56.

6. Etterson JR. Evolutionary potential of Chamaecrista fasciculata in relation to climate change. II. Genetic architecture of three populations reciprocally planted along an environmental gradient in the great plains. Evolution. 2004:58(7):1459-71.

7. Evanno G, Regnaut S, Goudet J. Detecting the number of clusters of individuals using the software STRUCTURE: a simulation study. Mol Ecol. 2005;14(8):2611-20

8. Falush D, Stephens M, Pritchard JK. Inference of population structure using multilocus genotype data: linked loci and correlated allele frequencies. Genetics. 2003;164(4):1567-87.

9. Falush D, Stephens M, Pritchard JK. Inference of population structure using multilocus genotype data: dominant markers and null alleles. Mol Ecol Notes. 2007:7(4):574-8.

10. Fenster CB. Gene flow in Chamaecrista fasciculata (Leguminosae) I. Gene dispersal. Evolution. 1991:45(2):398-409.

11. Fenster CB. Gene flow in Chamaecrista fasciculata (Leguminosae) II. Gene establishment. Evolution. 1991:45(2):410-22.

12. Fenster $C B$. Mirror image flowers and their effect on outcrossing rate in Chamaecrista fasciculata (Leguminosae). Am J Bot. 1995:82(1):46-50.

13. Fenster CB, Galloway LF. Inbreeding and outbreeding depression in natural populations of Chamaecrista fasciculata (Fabaceae). Conserv Biol. 2000:14(5):1406-12.

14. Fenster CB, Vekemans X, Hardy OJ. Quantifying gene flow from spatial genetic structure data in a metapopulation of Chamaecrista fasciculata (Leguminosae). Evolution. 2003;57(5):995-1007.

15. Gleason HA, Cronquist A. Manual of vascular plants of Northeastern United States and adjacent Canada. 2nd edition, The New York Botanical Garden, Bronx, NY. 1991. http://dx.doi.org/10.21135/893273651.001.

16. Greene SL, Kisha TJ, Yu LX, Parra-Quijano M. Conserving plants in gene banks and nature: investigating complementarity with Trifolium thompsonii Morton. PLoS ONE. 2014;9(8):e105145.

17. Jakobsson M, Rosenberg NA. CLUMPP: a cluster matching and permutation program for dealing with label switching and multimodality in analysis of population structure. Bioinformatics. 2007;23(14):1801-6.
18. Johnson RC, Kisha TJ, Pecetti L, Romani M Richter P Characterization of Poa supina from the Italian Alps with AFLP markers and correlation with climatic variables. Crop Sci. 2011:51(4):1627-36.

19. Kisha T, Kodin K. Genetic diversity of North American Wild kidney bean (Phaseolus polystachios) in the Eastern United States. Conference poster from ashs.confex.com.

20. Legume Phylogeny Working Group. Legume phylogeny and classification in the 21st century: progress, prospects and lessons for other species-rich clades. Taxon. 2013:62(2):217-48.

21. Legume Phylogeny Working Group, Azani N, Babineau M, Bailey CD, Banks H, Barbosa AR, Pinto RB, Boatwright JS, Borges LM, Brown GK, Bruneau A, Candido E. A new subfamily classification of the Leguminosae based on a taxonomically comprehensive phylogeny The Legume Phylogeny Working Group (LPWG). Taxon. 2017;66(1):44-77.

22. Parker MA, Kennedy DA. Diversity and relationships of bradyrhizobia from legumes native to eastern North America. Can J Microbiol. 2006;52(12):1148-57.

23. Peakall R, Smouse PE. GENALEX 6: genetic analysis in Excel. Population genetic software for teaching and research. Mol Ecol Notes. 2006;6(1):288-95.

24. Peakall R, Smouse PE. GenAlEx 6.5: genetic analysis in Excel. Population genetic software for teaching and research-an update. Bioinformatics. 2012:28:2537.

25. Prevosti A, Ocana J, Alonso G. Distances between populations of Drosophila subobscura, based on chromosome arrangement frequencies. Theor Appl Genet. 1975;45(6):231.

26. Pritchard JK, Stephens M, Donnelly P. Inference of population structure using multilocus genotype data. Genetics. 2000;155(2):945-59.

27. Rohlf FJ. NTSYSpc: numerical taxonomy system. Exeter Software: version 2; 2009

28. Rosenberg NA. DISTRUCT: a program for the graphical display of population structure. Mol Ecol Notes. 2004;4(1):137-8.

29. Singer SR, Maki SL, Farmer AD, Ilut D, May GD, Cannon SB, Doyle JJ. Venturing beyond beans and peas: what can we learn from Chamaecrista? Plant Physiol. 2009;151(3):1041-7.

30. Stanton-Geddes J, Anderson CG. Does a facultative mutualism limit species range expansion? Oecologia. 2011;167(1):149-55.

31. Stanton-Geddes J, Tiffin P, Shaw RG. Role of climate and competitors in limiting fitness across range edges of an annual plant. Ecology. 2012:93(7):1604-13.

32. Vekemans X. 2002. AFLP-surv version 1.0. Distributed by the author. Laboratoire de Génétique et Ecologie Végétale, Université Libre de Bruxelles, Belgium, 16.

33. Vos $P$, Hogers $R$, Bleeker M, Reijans M, Lee TVD, Hornes M, Friters A, Pot J, Paleman J, Kuiper M, Zabeau M. AFLP: a new technique for DNA fingerprinting. Nucleic Acids Res. 1995;23(21):4407-14.
Ready to submit your research? Choose BMC and benefit from:

- fast, convenient online submission

- thorough peer review by experienced researchers in your field

- rapid publication on acceptance

- support for research data, including large and complex data types

- gold Open Access which fosters wider collaboration and increased citations

- maximum visibility for your research: over 100M website views per year

At BMC, research is always in progress.

Learn more biomedcentral.com/submissions 